Solar Prominences.-An important memoir on solar prominences has been published by Mr. and Mrs. Evershed (Memoirs Kodaikanal Obs., vol. i., part ii.). The total number of prominences observed and photographed at the sun's limb at Kenley and Kodaikanal during the years 1890 to 1914 was about 71,000 , and in recent years the denser prominences have also been photographed as absorption markings on the sun's disc. This wealth of abservational material is discussed from many points of view. It results, among other conclusions, that there are four belts, two in each hemisphere, which are specially prolific in prominences. The low-latitude belts are coincident with the sunspot zones, and in these the prominences vary in number with the spots, although direct association of spots and prominences is comparatively rare. In the high-latitude belts the prominences are most frequent between spot minimum and spot maximum; they reach the pole about spot maximum, and die out there, to form again in latitude $\pm 50^{\circ}$. Magnetic storms appear to be more closely related to spots than to prominences, but it is possible that an overlying prominence is a necessary condition for a spot to produce a magnetic storm. Large high prominences are roughly divisible into four classes, namely, broad massive prominences, tapering forms, diffused forms, and prominences in rows. Prominences associated with spots take the form of jets, rockets, or arches. The prevailing rocket type suggests the action of an intermittent explosive force in spots, which only partially neutralises gravity, while in the large masses gravity appears to be completely neutralised by the upward force. The density of prominences is probably very low, and it is suggested that the luminosity may be due to the internal energy of the atoms, possibly derived mainly by absorption of the intense solar radiation. Numerous photographs of prominences are reproduced.

\section{FUEL RESEARCH.}

$\Delta \mathrm{T}$ the request of the Board of Trade and other A Government departments, the Fuel Research Board has undertaken an investigation on the most suitable composition and quality of gas, and the minimum pressure at which it should be supplied, having regard to the desirability for economy in the use of coal, the adequate recovery of by-products, and the purposes for which coal is now used. The Research Board will also act in an advisory capacity. With the great extension of the use of gas for power and heating, and the possibility of using efficiently for illuminating purposes, by means of the incandescent mantle, gas of much lower illuminating value than formerly, more importance now attaches to calorific value than to candle-power. Practice has necessarily conformet to the altered conditions, for gas engineers have gone a good way in solving the problems involved in making the best use of coal in their industry, in the recovery of by-products, on which success so much depends, together with supplying a gas satisfactory for the wide and varied requirements. The industry has indeed been exceptional in the valuable research work done, its enterprise being shown in the establishment of the Livesey Laboratory at Leeds.

Possibly the Research Board will find little scope for improvement in the general production of coalgas, although no one would claim that finality has been reached, but some important problems remain for investigation, notably the production of low-temperature coke and the utilisation of the oils and very rich gas produced. The gas engineer has hitherto not regarded this question in an unprejudiced manner, whilst the advocates have generally been over-optimistic, so that independent investigation is really wanted. NO. 249I, VOL. 99]
There is also a wide field for investigating how cokeoven gas may be more extensively employed to supplement the output of suitably situated gasworks, and the more extended use of water-gas.

The Fuel Research Board, with the sanction of the Committee of the Privy Council for Scientific and Industrial Research, has appointed a committee of inquiry into the utilisation of Irish peat deposits. The terms of reference to the committee are as follows :"To inquire into and to consider the experience already gained in Ireland in respect of the winning, preparation, and use of peat for fuel and for other purposes, and to suggest what means shall be tàken to ascertain the conditions under which, in the most favourably situated localities, it can be profitably won, prepared, and used, having regard to the economic conditions of Ireland; and to report to the Fuel Research Board.'

Though the inquiries of the committee will ultimately lead up to the consideration of peat as a source of energy in central power stations, there are sound reasons why this aspect of the problem should be postponed to a later stage. On one hand, the Fuel Research Board is already organising an extensive inquiry into the problems of fuel economy in connection with power production, and the results of this inquiry will supply the fundamental data and information which will be required when the time comes for the consideration of any wide scheme of development in Ireland. On the other hand, any schemes of development must be based on a more exact knowledge than is at present available regarding the selection of the more favourably situated bogs and the possibilities of winning and transporting partially dried peat to centres at which it may be converted into marketable products. It is obvious, therefore, that the in. quiries of the committee are likely to be most fruitful if they are concentrated on the fundamental problems, for until these are settled no satisfactory progress can be made.

The following appointments have been made to the committee:-Sir John Purser Griffith (chairman), Prof. Hugh Ryan, Prof. Sydney Young, Mr. George Fletcher, and Prof. Pierce Purcell (secretary). All communications should be addressed to the Secretary, The Peat Inquiry Committee, University College, Dublin.

\section{GLASS TECHNOLOGY.}

THE newly formed Society of Glass Technology is to be warmly congratulated on the first number of its Journal, which has just appeared. The volume contains five original papers and a considerable number of abstracts dealing with glass and allied subjects. These abstracts, in which an endeavour is made to summarise the literature of the subject-including that appearing on the Continent so far back as the beginning of I9I5-form a most valuable feature, particularly as the difficult work of abstracting has been well done. If, at a later stage, the society could undertake to carry the abstracts back-if possible for a period of ten years - they would earn the gratitude of all concerned with glass. There is, of course, always the difficulty in such abstracts of discriminating between the wheat and the chaff, so as to avoid burdening the pages with abstracts of valueless material; such discrimination, however, demands a degree of intimate familiarity with the subject in both its industrial and scientific aspects which is scarcely obtainable in the case of glass, since this has only recently begun to receive in this country the attention which it deserves. It is, further, a little doubtful whether the editor of this Journal has been wise in including abstracts on purely optical subjects, since these are more 
fully dealt with by a special society (the Optical Society), and overlapping is most undesirable in matters of publication.

The original papers attain a very creditable standard for so young a society and so new a subject. Prof. Boswell's work on British glass sands is already widely known and appreciated, since it has already been more or less completely published elsewhere. Mr. C. J. Peddle describes trials of British sands as substitutes for some of foreign origin, and his results are extremely hopeful, provided that careful treatment in regard to grading and washing is applied to the British materials. Mr. F. Twyman deals with the annealing of glass, and describes a method of testing the glass for strain and for its disappearance by means of a special form of polarimeter; the modification ascribed to Mr. F. E. Lamplough, however, is not novel, as the writer saw it in use more than fourteen years ago. Nor does Mr. Twyman make it quite clear that his reasoning is not applicable to any but thin glass vessels, such as the beakers he refers to. In such thin glassware all that is required is uniform cooling from the "annealing temperature" of Mr. Twyman; in thicker glass, however, such uniformity as between exterior and interior portions can be obtained only by very slow cooling.

Apart from detailed criticism of particular points, the whole volume clearly shows the vitality of the new society and the need for the co-ordinated study of glass and glass manufacture from the scientific point of view. It is to be hoped that all branches of the British glass industry, which has received a rejuvenating impulse from the war, will support the new society and thus facilitate the co-operation of science in an industry that should be essentially scientific.

\section{PLANKTON RESEARCH AT PLYMOUTH.}

THE May number of the Journal of the Marine

Biological Association is devoted to an interesting account of the investigations of the plankton of the sea outside Plymouth Breakwater, made during the year September, rgi5, to September, IgI6. The main systematic research has been conducted by Miss Lebour, while Dr. Allen describes post-larval stages of fishes, and Mr. Matthews gives an account of the variation in the quantity of phosphoric acid present in the seawater. Miss Lebour used Lohmann's method of centrifuging small volumes of sea-water (50 c.c.), and then actually counting the organisms so obtained. Her results are in general agreement with those of Lohmann (at Kiel) and Herdman and Scott (at Port Erin). There are well-marked seasons of abundance of microplanktonic organisms, diatoms occurring in greatest quantity some time in the spring or early summer, and then again in the autumn, while Peridiniales attain their maximum of seasonal abundance a little later than the diatoms. The Peridiniales have been very thoroughly investigated, and Miss Lebour describes eight species which are new to science and twenty-one species which have not hitherto been recorded from British seas. She also gives some records of the occurrence of larval Trematodes, free-swimming in the sea, and descriptions of the Helminth parasites of Sagitta. These worms have been noticed many times, and some of them are very familiar to planktologists, but no sound identifications have been made prior to the research now under notice. Sagitta is a host for larval forms of Derogenes varicus and Pharyngora bacillaris, both well-known fish Trematodes. A larval Ascaris also occurs, and two larval Cestodes, the species of which are not identifiable.

Mr. Matthews gives detailed accounts of his methods of determining the exceedingly small quantities of NO. 249I, VOL. 99] phosphoric acid which occur in sea-water, at the most about $0.06 \mathrm{mg}$. of $\mathrm{P}_{2} \mathrm{O}_{5}$ per litre. There is a well. marked maximum at nearly the end of the year (in the darkest days). The variations are dependent upon the metabolism of marine plants, and the minimum quantity of phosphoric acid occurs in April and May-that is, at about the time when holophytic plants are taking most food substance from the sea-water. The larger algæ seem to be the principal factors for the curve of variation in quantity of phosphoric acid not being the reverse of that for variation in abundance of diatoms, as was at first expected.

J. J.

\section{CORRECTION FOR ATMOSPHERIC RE-}

\section{FRACTION IN GEODETIC OPERATIONS. ${ }^{1}$}

THE memoir before us is concerned with operations between distant stations, especially those differing considerably in altitude. The author quotes Helmert's elaborate formula, which gives the correction as a function of gravity, atmospheric pressure, coefficient of expansion of air, tension of aqueous vapour, temperature, and vertical temperature gradient. The values deduced from the formula are compared with those obtained by observa. tion over several bases in Italy and the Alps. The results are grouped both by months and by hours of the day; they show in a clear manner that there are both diurnal and annual variations in the refraction coefficient, which appear to be mainly due to the changes in the vertical temperature gradient. The following table shows the results of two series, the coefficients in the first column being deduced from the formula, and in the second by experiment. The third column gives the observed vertical temperature gradient.

\begin{tabular}{|c|c|c|c|c|}
\hline \multirow{2}{*}{ Months } & & \multicolumn{2}{|c|}{$\begin{array}{l}\text { Coefficient of refraction at } \\
\text { noon }\end{array}$} & \multirow{2}{*}{$\begin{array}{l}\text { Diminution of } \\
\text { temperature for } \\
\text { xoo m. altitude } \\
\text { in degrees } \\
\text { Centigrarle }\end{array}$} \\
\hline & & $\begin{array}{c}\text { From } \\
\text { formula }\end{array}$ & $\begin{array}{c}\text { From } \\
\text { experiment }\end{array}$ & \\
\hline Jan., Dec. & $\cdots$ & 0.175 & - & 0.44 \\
\hline Feb., Nov. & $\cdots$ & $0 \cdot 170$ & $0 \cdot 18 \mathrm{I}$ & 0.55 \\
\hline Mar., Oct. & $\cdots$ & 0.158 & 0.168 & 0.68 \\
\hline Apr., Sept. & $\ldots$ & 0.154 & 0.159 & $0 \cdot 74$ \\
\hline May, Aug. & $\cdots$ & $0 \cdot 145$ & 0.154 & 0.79 \\
\hline June, July & $\cdots$ & 0.144 & O. I 53 & 0.79 \\
\hline
\end{tabular}

The results of several measures of altitudes over long bases in Italy (length $23 \mathrm{~km}$., difference of altitude $900 \mathrm{~m}$.) show a range of somewhat over a metre, and indicate that better results are obtained by using the meteorological data of the lower station only than by combining those of both stations. The memoir closes with a table arranged to facilitate the application of the correction for temperature to measured altitudes in surveying.

A. C. D. Crommelin.

\section{THE COMPLEXITY OF THE CHEMICAL ELEMENTS. ${ }^{2}$}

\section{II.}

The Periodic Law and Radio-active Change.

THE second line of advance interprets the periodic law. It began in IgII with the cbservation that the product of an a-ray change always occupied a place in the periodic table two places removed from the parent in the direction of diminishing mass, and that in subsequent changes where $\alpha$ rays are not expelled, the product frequently reverts in chemical character to

1 "Sulla Determinazione del Coefficiente di Rifrazione Terrestre in Base ad Elementi Meteorologici." By Vincenzo Reina. (Roma: R. Accademia dei

Lincei, ser. v., vol. xil., Fasc. ii, r $9 \times 6$.)
2 Discourse delivered at the Royal Institution on Friday, May $x 8$, by Prof. Frederick Sordy, F.R.S. Continued from p. 418 . 